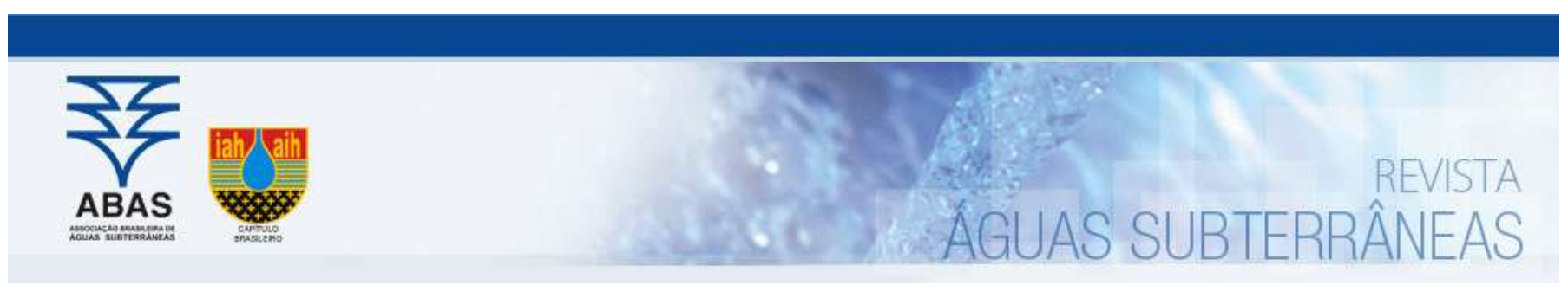

Artigos

\title{
Sistemas Aquíferos da porção centro-norte da Bacia Sanfranciscana e estimativa do fluxo regional
}

\section{Aquifer systems of the central-north portion of the Sanfranciscana Basin and regional flow estimate}

\author{
Flavio de Paula e Silva1,2; Hung Kiang Chang 2,3 \\ ${ }^{1}$ Geodata - Consultoria e Projetos Hidrogeológicos, São Paulo, SP \\ 2 Lebac - Laboratório de Estudos de Bacias, Instituto de Geociências e Ciências Exatas / Centro de Estudos Ambientais (CEA), UNESP - \\ Campus de Rio Claro, SP \\ ${ }^{3}$ Departamento de Geologia Aplicada, Instituto de Geociências e Ciências Exatas, UNESP - Campus de Rio Claro, SP

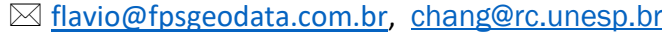

\begin{tabular}{ll} 
& Resumo \\
\cline { 2 - 3 } Palavras-chave: & Com área aproximada de $125.000 \mathrm{~km}^{2}$, a porção centro-norte da Bacia Sanfranciscana abriga o Sistema Aquífero Urucuia, res- \\
ponsável pela manutenção do fluxo de base dos tributários da margem esquerda da Bacia do Rio São Francisco. Recentemente, \\
Aquífero Urucuia. & estudos de subsuperfície identificaram aquíferos permo-triassicos subjacentes, cujas rochas reservatório eram atribuídas, ante- \\
Aquíferos permo-triassicos. & riormente, ao Sistema Aquífero Urucuia. Esses aquíferos foram correlacionados aos aquíferos Sambaíba e Motuca, da Bacia do \\
Fluxos locais. & Parnaíba. O complexo arcabouço hidrogeológico configurado por este grupo de aquíferos favoreceu a coexistência de sistemas \\
Fluxo regional. & de fluxo locais e regional. Os sistemas de fluxo locais, caracterizados por apresentarem áreas de recarga e de descarga adjacentes \\
Hidroestratigrafia. & e dirigidos principalmente no sentido leste, drenam $991 \mathrm{~m}^{3} / \mathrm{s}$ das águas do SAU como fluxo de base para as bacias dos rios São \\
& Francisco, Tocantins e Parnaíba. O sistema de fluxo regional estimado em 29 m³/s, com direção de escoamento NW, paralela ao \\
& eixo longitudinal da Bacia Sanfranciscana, descarrega a água subterrânea dos aquíferos permo-triassicos para a Bacia do Rio \\
& Tocantins. A retirada de água por meio de poços tubulares profundos dos reservatórios permo-triassicos afeta o escoamento de \\
base dos rios tributários do Rio Tocantins. Face às peculiaridades hidrogeológicas constatadas, os modelos atuais de gestão de \\
recursos hídricos da Bacia Sanfranciscana devem ser reavaliados.
\end{tabular}

Keywords

Urucuia Aquifer.

Permo-triassic aquifers.

Local flow.

Regional flow.

Hydrostratigraphy.

Revisado por pares.

Recebido em: 30/03/2018.

Aprovado em: 30/05/2018.

\begin{abstract}
Urucuia Aquifer System (UAS) lies in the north-central portion of the Sanfranciscana Basin and it occupies an area of approximately $125,000 \mathrm{~km}^{2}$. UAS is responsible for sustaining the baseflow of the left margin tributaries of the São Francisco River Basin. Recently, subsurface studies have identified underlying permo-triassic aquifers, which have been previously considered as part of the Urucuia Aquifer System. These aquifers are attributed to belong to Sambaíba and Motuca formations of the Parnaíba Basin. Local groundwater flow systems, characterized by discharging along the adjacent recharge areas, shows a predominantly east flow direction, contributing $991 \mathrm{~m}^{3} / \mathrm{s}$ to the baseflow of the São Francisco, Tocantins and Parnaíba River basins. The regional NW flow system, parallel to the longitudinal axis of the Sanfranciscana Basin, discharges $29 \mathrm{~m} 3 / \mathrm{s}$ of groundwater of the permotriassic aquifers to the Tocantins River Basin. The groundwater withdrawal by deep wells producing from the permo-triassic reservoirs is likely to affect the baseflow of the Tocantins State Rivers. Given the hydrogeological peculiarities observed, the current models of the Sanfranciscana Basin water resources management need to be reassessed.
\end{abstract}

\section{INTRODUÇÃO}

A cobertura fanerozoica que se distribui sobre o substrato proterozoico da Bacia do São Francisco é distinguida como Bacia Sanfranciscana (SGARBI, 1989). De formato alongado N-S com aproximadamente $1.100 \mathrm{~km}$ de comprimento e até $270 \mathrm{~km}$ de largura máxima, a Bacia Sanfranciscana estende-se desde o norte/noroeste do estado de Minas Gerais até o sul dos estados de Maranhão e
Piauí, e sudeste de Tocantins (Figura 1). Delimita-se a sul com a Bacia do Paraná pelo Alto do Paranaíba, a norte com a Bacia do Parnaíba pelo Arco do São Francisco, e segmenta-se nas sub-bacias Abaeté, a sul, e Urucuia, ao centro-norte, pelo Alto de Paracatu (CAMPOS \& DARDENNE, 1997). 
Figura 1 - Contexto geológico da porção centro-norte da Bacia Sanfranciscana e do Grupo Urucuia (modificado de CPRM, 2007). N-S e E-W são seções geológicas apresentadas nas figuras 2 e 3

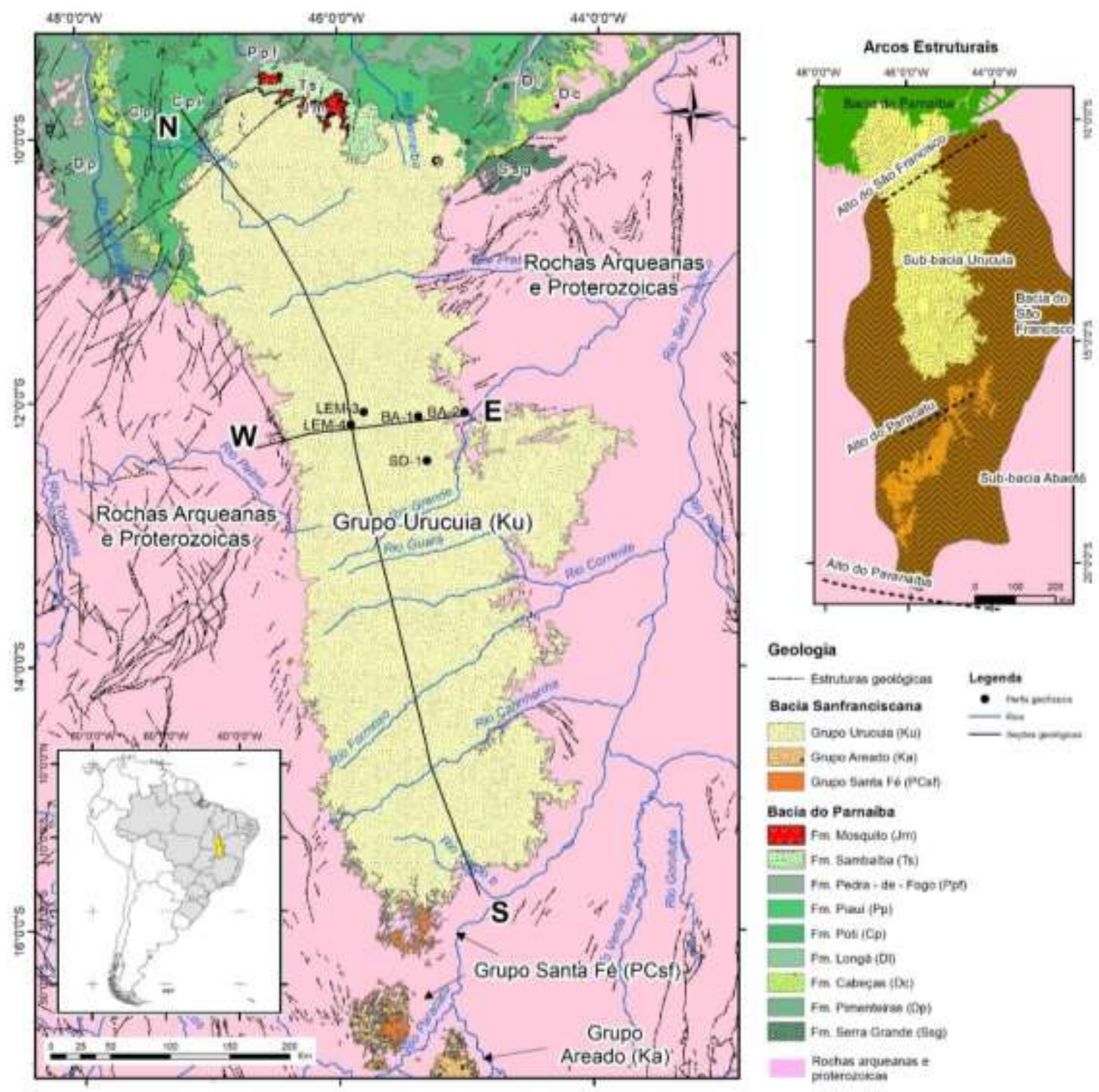

A porção centro-norte da Bacia Sanfranciscana encerra rochas neocretácicas do Grupo Urucuia e, localmente, permo-triassicas do Grupo Santa Fé. Importantes reservas de água subterrânea, de excelente qualidade, estão armazenadas no Sistema Aquífero Urucuia (SAU), constituído pelas rochas do Grupo Urucuia.

O SAU distribui-se por pouco mais $125 \mathrm{mil} \mathrm{km}^{2}$ e cobre parte de três grandes bacias hidrográficas: Rio São Francisco $\left(98.700 \mathrm{~km}^{2}\right)$, Rio Tocantins $\left(20.650 \mathrm{~km}^{2}\right)$ e Rio Parnaíba $\left(7.080 \mathrm{~km}^{2}\right)$. Sobrepõe-se a rochas proterozoicas no bordo sul, e aos aquíferos permo-triassicos Motuca e Sambaíba, da Bacia do Parnaíba, nas demais porções da bacia (CHANG; PAULA e SILVA, 2015). Neste cenário hidrogeológico complexo, a água subterrânea escoa por diferentes unidades hidroestratigráficas, distribuindo-se em sistemas de fluxo locais e regional.

Com base em dados existentes, o presente estudo demonstra que importantes volumes de água subterrânea dos aquíferos permo- triassicos são transferidos para a Bacia do Rio Tocantins pelo fluxo regional. Segundo esta concepção, os volumes transferidos devem ser considerados no balanço hídrico dos modelos de gestão da Bacia Sanfranciscana.

\section{ARCABOUÇO HIDROGEOLÓGICO DA PORÇÃO CENTRO-NORTE DA BACIA SANFRANCISCANA}

Com base nas análises de sucessões sedimentares, correlação de perfis geofísicos e em dados altimétricos do contato dos sedimentos fanerozoicos com o Grupo Bambuí, Chang \& Paula e Silva (2015) esboçaram o arcabouço de subsuperfície da porção centro-norte da Bacia Sanfranciscana. Os autores mostraram que as rochas constituintes do SAU sobrepõem-se em discordância erosiva às rochas neoproterozoicas do Grupo Bambuí, no bordo sul, e às formações permo-triassicas Motuca e Sambaíba, da Bacia do Parnaíba, nas demais porções da bacia (figuras 2 e 3 ). 
Figura 2 - Seção geológica N-S ao longo do eixo longitudinal da porção centro-norte da Bacia Sanfranciscana. Localização da seção na Figura 1. Poço LEM-4 = 2-ANP-3-BA. BP=Bacia do Parnaíba; BSF=Bacia Sanfranciscana

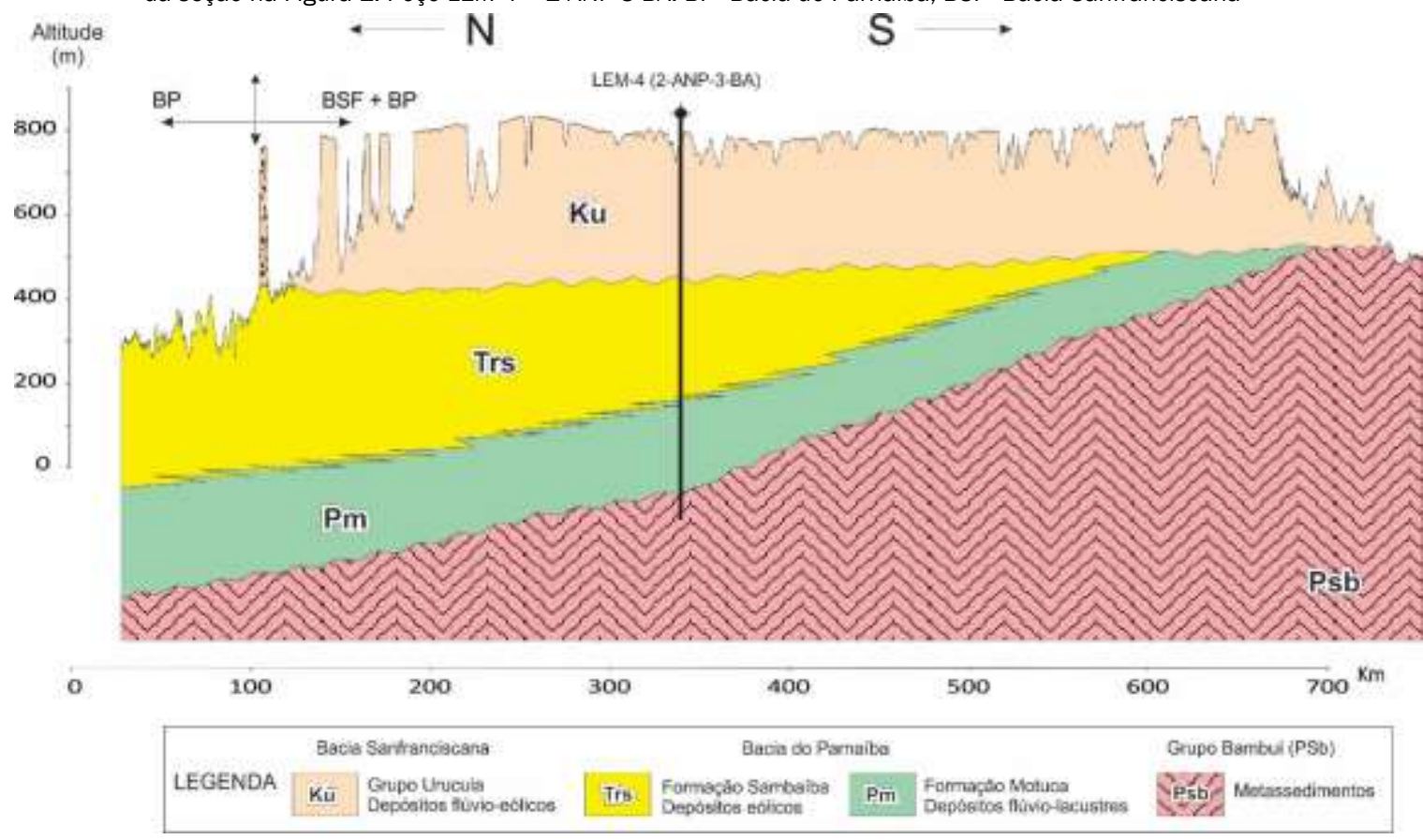

Figura 3 - Seção geológica W-E (A) e seção sísmica SW-NE (B) ao longo do eixo transversal da porção centro-norte da Bacia Sanfranciscana. Localização da seção geológica na Figura 1 e da seção sísmica na própria figura. Poço LEM-4 = 2-ANP-3-BA. BP=Bacia do Parnaíba. BSF=Bacia Sanfranciscana

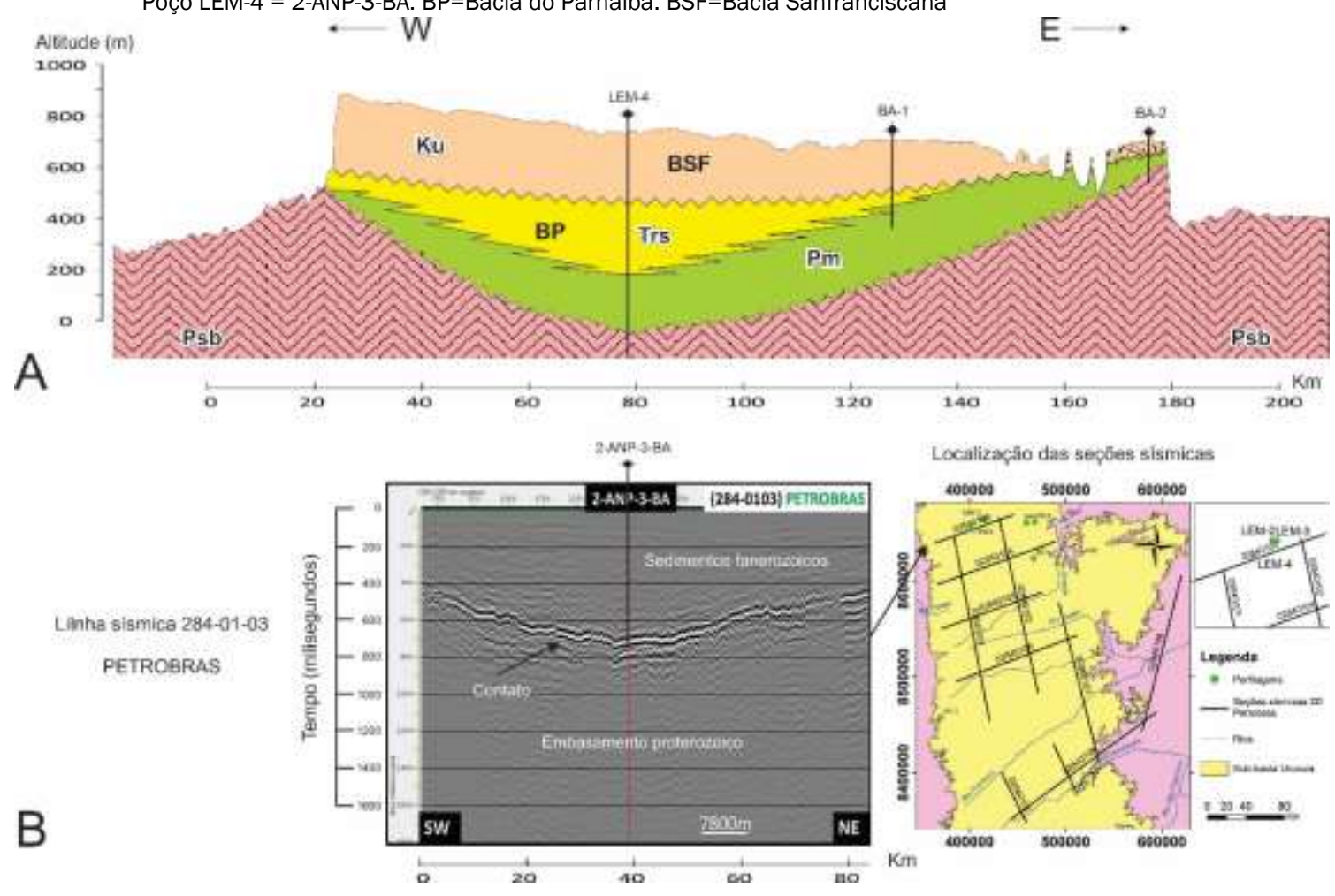

A seção longitudinal N-S (Figura 2) mostra que o Grupo Urucuia recobre discordante e sucessivamente, de norte para sul, rochas progressivamente mais antigas, representadas pelas formações Sambaíba (Triássico), Motuca (Permiano) e Grupo Bambuí (Proterozoico). A seção transversal E-W (Figura $3 \mathrm{~A}$ ) mostra o Grupo Urucuia assentado discordantemente sobre as unidades permo-triassicas da Bacia do Parnaíba, por sua vez assentadas sobre o Grupo Bambuí.

Essas duas seções sugerem uma calha deposicional pretérita no

substrato da bacia, que acumulou e preservou sedimentos relacionados à Bacia do Parnaíba. A ocorrência localizada de sedimentos glaciogênicos do Grupo Santa Fé pode indicar que a sedimentação paleozoica associada à Bacia do Parnaíba tenha se estendido até as porções meridionais da Bacia Sanfranciscana.

Evidências comprobatórias dessa calha deposicional foram apresentadas por Pereira et al. (2015), com base na reinterpretação de 11 linhas sísmicas 2D, calibradas com os dados da perfuração do poço 2-ANP-3-BA (Figura 3B). A delimitação da calha no segmento 
meridional da bacia é prejudicada pela descontinuidade das linhas sísmicas.

\section{UNIDADES AQUÍFERAS DA PORÇÃO CENTRO-NORTE DA BACIA SANFRANCISCANA}

Três sistemas aquíferos foram reconhecidos no intervalo fanerozoico da porção centro-norte da Bacia Sanfranciscana (CHANG;
PAULA e SILVA, 2015): Sistema Aquífero Urucuia (SAU), Sistema Aquífero Sambaíba e Sistema Aquífero Motuca. 0 arranjo hidroestratigráfico.

O SAU se estende por área de aproximadamente $125.000 \mathrm{~km}^{2} \mathrm{da}$ Bacia Sanfranciscana (Figura 1). Seus limites setentrionais ainda não estão claramente definidos e necessitam de uma revisão (CHANG; PAULA e SILVA, 2015).

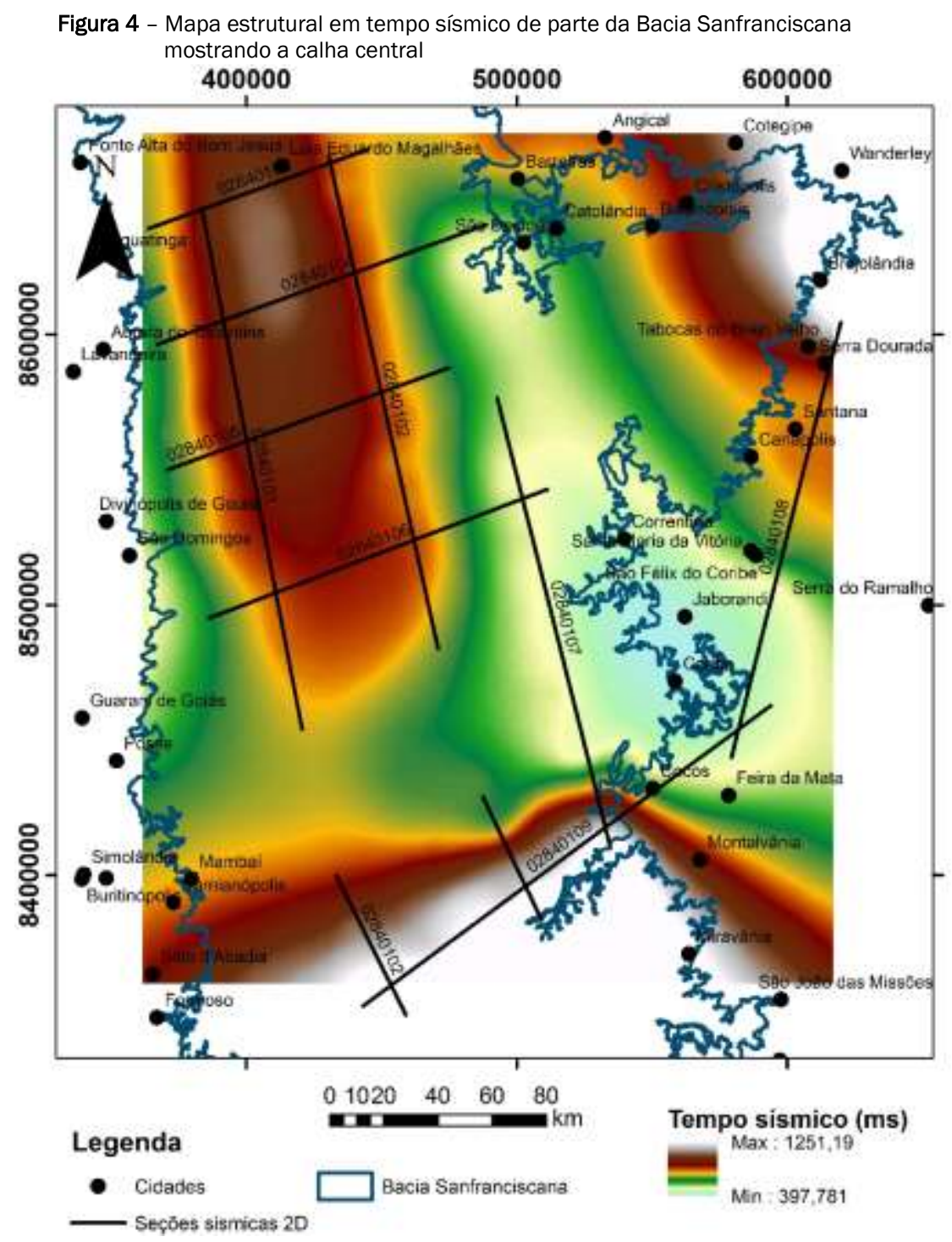

Fonte: Modificado de Pereira et al. (2015)

O Sistema Aquífero Urucuia compreende sucessão predominantemente arenosa depositada num sistema eólico de campo de dunas com interações de um sistema fluvial entrelaçado, com espessuras preservadas variáveis, com máxima de 350 metros. O SAU é um exemplo clássico de aquífero livre, do tipo poroso, de extensão regional e relativamente homogêneo. Apresenta condutividades hidráu licas variando de $2,7 \times 10^{-7} \mathrm{~m} / \mathrm{s}$ a $4,39 \times 10^{-4} \mathrm{~m} / \mathrm{s}$, transmissividades de $1,53 \times 10^{-5} \mathrm{~m}^{2} / \mathrm{s}$ a $4,1 \times 10^{-2} \mathrm{~m}^{2} / \mathrm{s}$ e porosidades efetivas de 14\% a 17\% (p.ex., LIMA, 2000; SCHUSTER et al., 2002). As vazões extraídas por poços podem superar $600 \mathrm{~m}^{3} / \mathrm{h}$ (ANA, 2013). As reservas hídricas permanentes são estimadas em $1.300 \mathrm{~km}^{3} \mathrm{e}$ as renováveis em 22,37 km³/ano (ANA, 2016). As águas do SAU possuem baixa concentração iônica, com médias de sólidos totais dis- solvidos (STD) variando de $29 \mathrm{mg} / \mathrm{L}$ a $48 \mathrm{mg} / \mathrm{L}$ e composição isotópica similar às águas superficiais, indicando existência de conexão entre elas (AQUINO et al., 2003).

O Aquífero Sambaíba faz parte dos aquíferos permo-triassicos da Bacia do Parnaíba e é constituído por arenitos eólicos da Formação Sambaíba. São desconhecidos registros de afloramentos de rochas dessa unidade na Bacia Sanfranciscana, mas é possível que possam ser encontrados nos bordos leste e oeste. Em subsuperfície, esse aquífero se adelgaça para sul até desaparecer no contato acima com o SAU, e se espessa no sentido oposto, na direção da Bacia do Parnaíba; a partir do eixo central da bacia, este aquífero se adelgaça tanto para o bordo leste quanto para o bordo oeste 
(CHANG; PAULA e SILVA, 2015). Sua espessura máxima constatada em subsuperfície foi de 269 metros (CHANG; PAULA e SILVA, 2015). Petri \& Fúlfaro (1983) apontam espessura máxima de 440 metros para a Formação Sambaíba, em subsuperfície, no interior da Bacia do Parnaíba. As características hidrodinâmicas e hidroquímicas do Aquífero Sambaíba, na Bacia Sanfranciscana, ainda são desconhecidas.

O Aquífero Motuca é composto por rochas permianas da Formação Motuca, da Bacia do Parnaíba. Seu arcabouço litológico compreende uma sucessão depositada em ambiente desértico com lagos associados, composta por arenitos finos a muito finos que se intercalam a siltitos vermelhos e camadas de carbonato (LIMA; LEITE, 1978). Registros de afloramentos de rochas da Formação Motuca não são conhecidos na Bacia Sanfranciscana. As espessuras do Aquífero Motuca diminuem gradativamente até as proximidades do limite meridional da porção centro-norte da Bacia Sanfranciscana; em direção à Bacia do Parnaíba, as espessuras devem aumentar ligeiramente; em relação ao eixo da bacia, as espessuras no bordo oriental são maiores do que no bordo ocidental. Em subsuperfície, a espessura máxima constatada na Bacia Sanfranciscana foi de 218 metros; a espessura máxima constatada na Bacia do Parnaíba foi de 296 metros (PETRI; FÚLFARO, 1983). As características hidrodinâmicas e hidroquímicas do Aquífero Motuca ainda são desconhecidas.
O relevo em chapadões com declividades predominantes menores de $2 \%$, a elevada condutividade hidráulica vertical do solo, da ordem de $10^{-3} \mathrm{~cm} / \mathrm{s}$ (ANA, 2016) e a homogeneidade litológica das rochas favorece a infiltração direta de água no aquífero, pelas precipitações atmosféricas.

A precipitação atmosférica média anual atinge 1.200 mm nas áreas do SAU. Praticamente $80 \%$ dessa água é consumida no processo de evapotranspiração e os $20 \%$ restantes concorrem com o escoamento superficial pela rede de drenagem. 0 escoamento de base das bacias hidrográficas representa $18 \%$ da precipitação anual e $90 \%$ do escoamento superficial. 0 escoamento de base corresponde, aproximadamente, à recarga anual do aquífero e é equivalente à reserva renovável, estimada em $218 \mathrm{~mm} /$ ano ou $757 \mathrm{~m}^{3} / \mathrm{s}$ (ANA, 2016).

Três importantes bacias hidrográficas do Brasil recebem contribuição de águas provenientes do fluxo de base do SAU (Figura 6). A maior contribuição é destinada à Bacia do Rio São Francisco, que recebe aporte de $731 \mathrm{~m}^{3} / \mathrm{s}$; outros $215 \mathrm{~m}^{3} / \mathrm{s}$ são liberados para a Bacia do Rio Tocantins e apenas $45 \mathrm{~m}^{3} / \mathrm{s}$ são descarregados para a Bacia do Rio Parnaíba. A contribuição do SAU alcança entre $80 \%$ e $90 \%$ da vazão total do Rio São Francisco nos períodos de estiagem (ANA, 2016).

\section{COMPORTAMENTO DO FLUXO SUBTERRÂNEO}

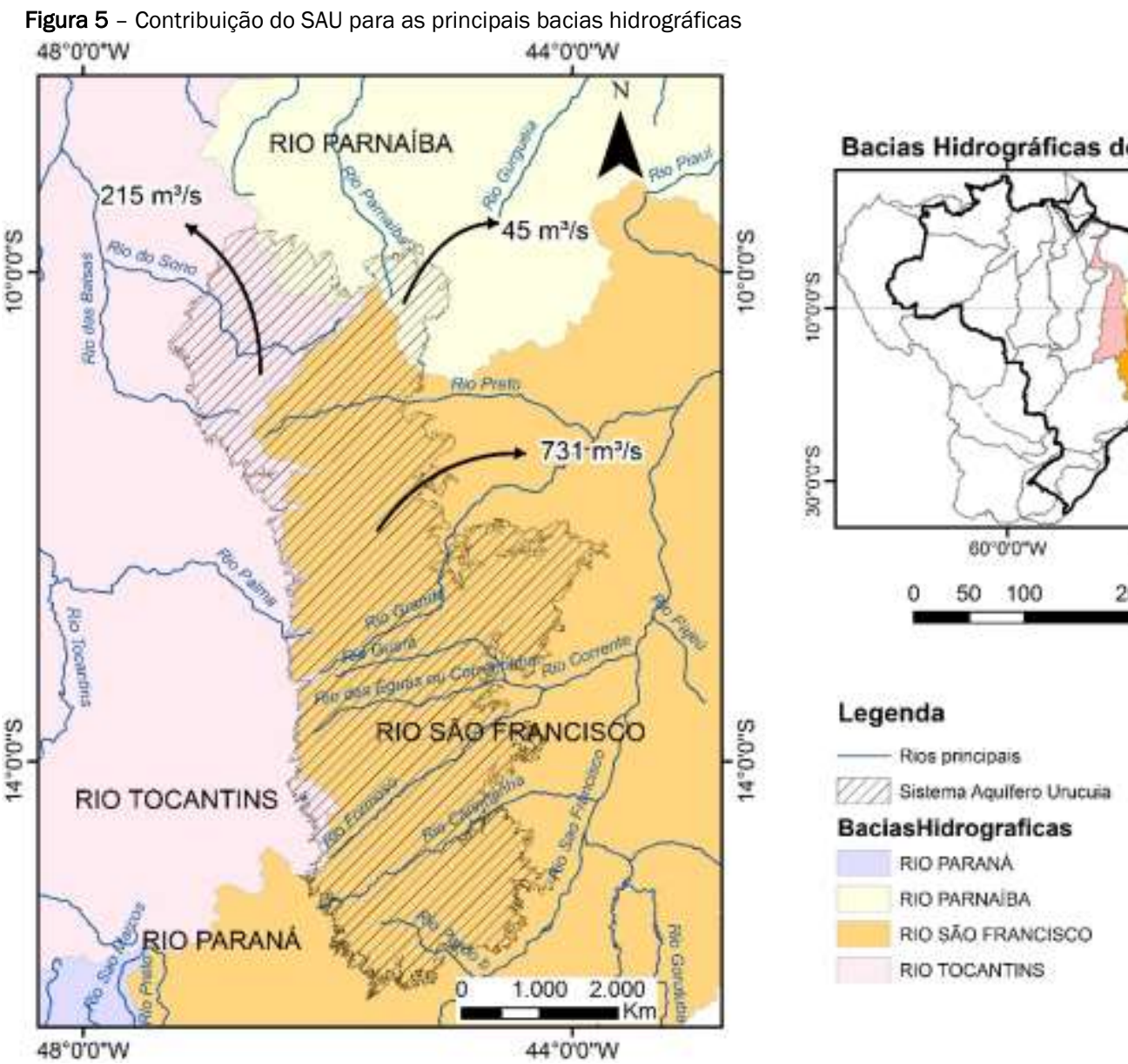

O fluxo principal das águas subterrâneas do SAU se dirige para leste, no mesmo sentido do escoamento superficial, a partir do divisor hi- drogeológico situado nas proximidades do bordo oeste da bacia, desaguando nas bacias contribuintes do Rio São Francisco (Figura 6). 
A partir desse divisor, no sentido oposto, uma parcela do fluxo subterrâneo é desviada para a Bacia do Tocantins. No extremo norte, divisores separam o fluxo subterrâneo que se dirige para Bacia do Rio São Francisco, daqueles que se dirigem para as bacias dos Rios Tocantins e Parnaíba. Na extremidade meridional da bacia, o fluxo subterrâneo desvia-se para sul, em direção ao Rio São Francisco. No bordo oriental, uma área com relevo alçado e caimento no sentido oeste, que se destaca como um apêndice do corpo principal do aquífero, tem o fluxo subterrâneo escoado para oeste, no sentido contrário ao do fluxo principal.

Figura 6 - Mapa potenciométrico do SAU

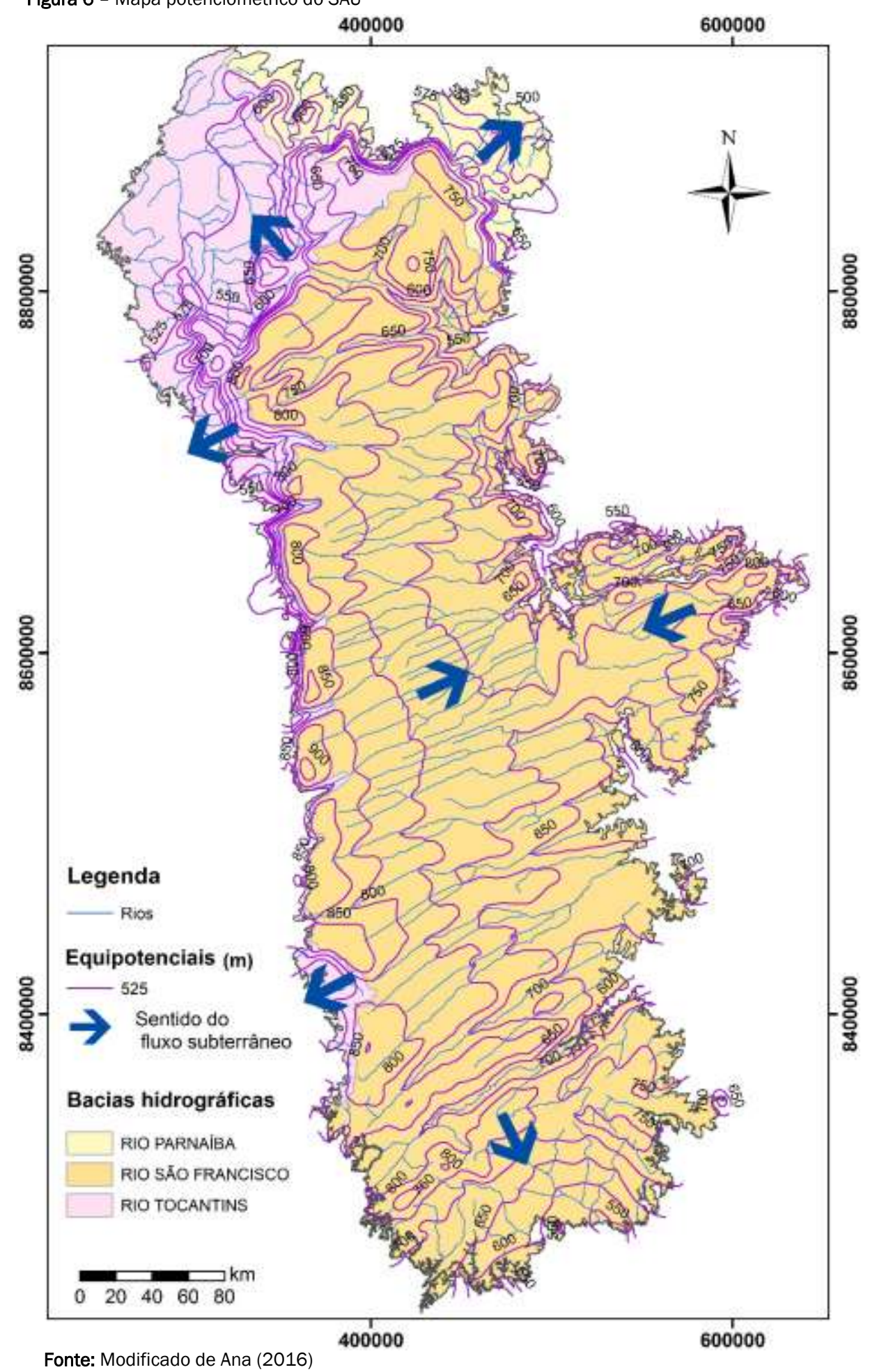

São inúmeros os cursos de água superficiais da porção centro-norte da Bacia Sanfranciscana que drenam as águas do SAU para fora de seus limites. Esses cursos superficiais dão origem a uma série de bacias adjacentes, nas quais as áreas de recarga de águas subterrâneas correspondem às porções mais elevadas do terreno e as áreas de descarga correspondem aos vales dos rios. A superfície potenciométrica do aquífero acompanha ligeiramente a topografia do terreno e cada bacia exerce controle sobre as direções do fluxo subterrâneo, dando origem a sistemas de fluxo locais (Figura 7). 
Figura 7 - Seção N-S esquemática baseada na Figura 2, mostrando os sistemas de fluxo subterrâneo locais e regional na porção centro-norte da Bacia Sanfranciscana. Notar que os sistemas locais ocorrem nas porções mais superficiais do SAU, enquanto o sistema regional tem o fluxo subterrâneo profundo e dirigido para a Bacia do Rio Tocantins

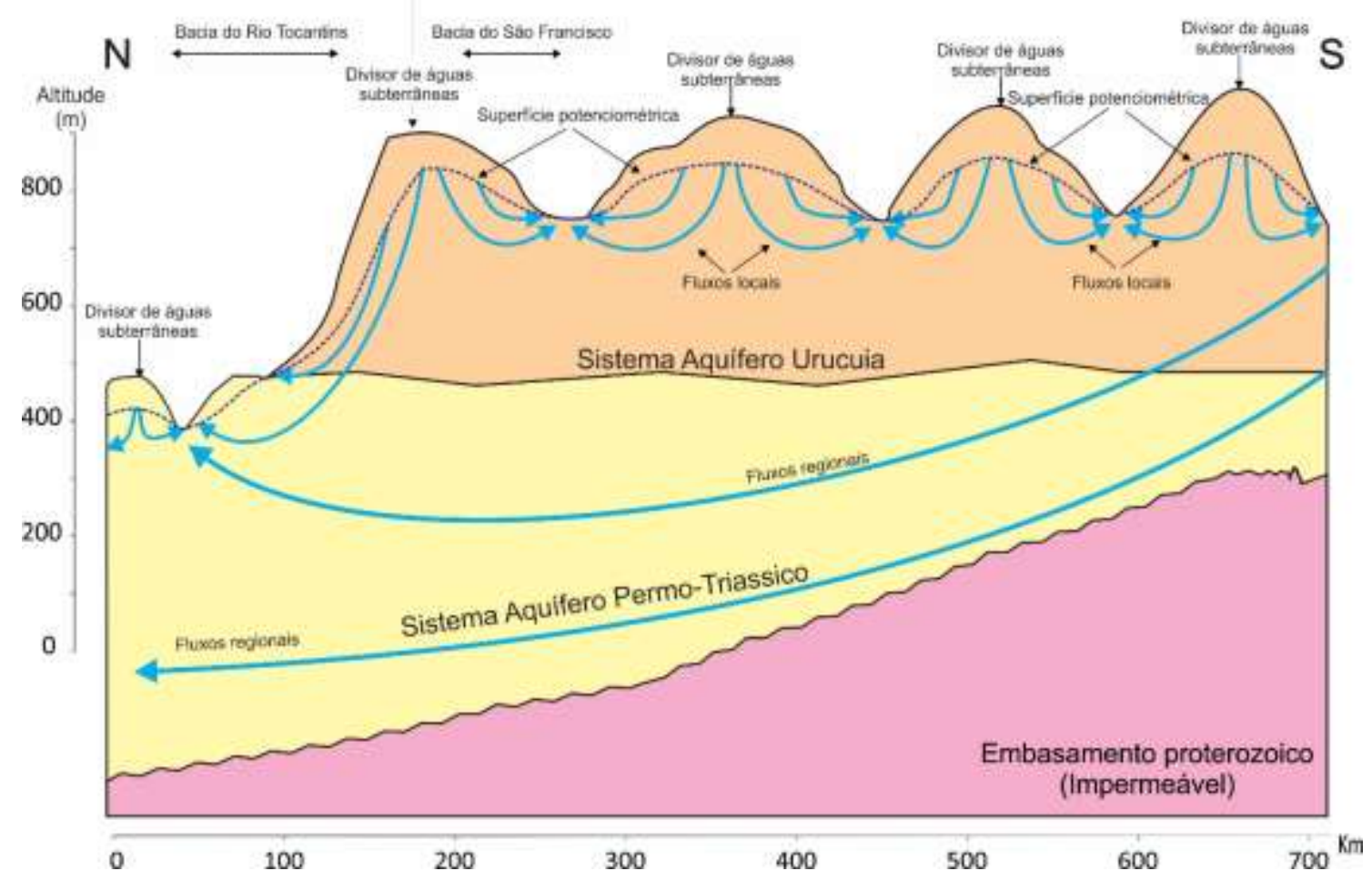

Fetter (2001) esclarece que sistemas de fluxo locais, em zonas úmidas, são formados devido às ondulações da superfície potenciométrica originadas pelas irregularidades topográficas do relevo. Os sistemas locais de fluxo são, em geral, responsáveis pela maior quantidade de água subterrânea descarregada para os cursos superficiais (EBERTS \& GEORGE, 2000). No caso do SAU, a contribuição total para os rios São Francisco, Tocantins e Parnaíba alcança 991 $\mathrm{m}^{3} / \mathrm{s}$ (ANA, 2013). Os sistemas locais são muito sensíveis às variações pluviométricas sazonais que, por sua vez, afetam a recarga e os níveis de água do aquífero.

Uma parcela menor de água subterrânea percola as rochas do SAU e atinge maiores profundidades, indo constituir a recarga profunda dos aquíferos permo-triassicos subjacentes. Em profundidade, essas águas movem-se lentamente até pontos de descarga situados na Bacia do Rio Tocantins, configurando um sistema de fluxo regional (Figura 7). 0 fluxo regional segue aproximadamente a direção NW, paralela ao eixo longitudinal da bacia, e é controlado pela calha do embasamento que acomodou a sedimentação permo-triassica da Bacia Sanfranciscana (figuras 2 e 3). Nota-se que a direção do fluxo regional não coincide com a direção principal do fluxo local, fato que demonstra que as águas do escoamento profundo não contribuem com o escoamento de base do SAU para a Bacia do Rio São Francisco. Os sistemas de fluxo regionais são pouco afetados por variações sazonais de recarga, o que favorece a manutenção do escoamento subterrâneo e, consequentemente, a descarga dos rios (EBERTS \& GEORGE, 2000). Nos pontos de descarga dos fluxos regionais, a água subterrânea pode apresentar-se mais mineralizada e relativamente mais quente, em relação ao padrão normal da área.

Dados hidrológicos apresentados por ANA (2016) indicaram que as contribuições do SAU são de $45 \mathrm{~m}^{3} / \mathrm{s}$ para a Bacia do Rio Parnaíba, $215 \mathrm{~m}^{3} / \mathrm{s}$ para a Bacia do Rio Tocantins e $731 \mathrm{~m}^{3} / \mathrm{s}$ para a Bacia do Rio São Francisco (Tabela 1). As contribuições específicas do SAU (quociente da vazão de contribuição pela área da bacia) apontam que o maior valor dentre as bacias é $7,73 \mathrm{~L} / \mathrm{s} / \mathrm{km}^{2}$ e refere-se à contribuição específica do SAU para o Rio Tocantins (Tabela 1).

Tabela 1 - Contribuição do SAU às bacias hidrográficas dos rios São Francisco, Tocantins e Parnaíba (ANA, 2016)

\begin{tabular}{cccc}
\hline Bacias & $\begin{array}{c}\text { Área SAU } \\
\left(\mathrm{Km}^{2}\right)\end{array}$ & $\begin{array}{c}\text { Contribuição } \\
\left(\mathrm{m}^{3} / \mathrm{s}\right)\end{array}$ & $\begin{array}{c}\text { Contribuição específica } \\
\left(\mathrm{L} / \mathrm{s} / \mathrm{Km}^{2}\right)\end{array}$ \\
\hline Parnaíba & 7.361 & 45 & 6,11 \\
São Francisco & 109.129 & 731 & 6,70 \\
Tocantins & 27.831 & 215 & 7,73 \\
\hline
\end{tabular}


Considerando a contribuição específica para o Rio São Francisco como representativa da descarga do SAU, em razão da maior área de distribuição do aquífero nessa bacia, verifica-se um acréscimo de $1,03 \mathrm{~L} / \mathrm{s} / \mathrm{km}^{2}$ na contribuição específica para o Rio Tocantins. Este acréscimo pode representar parte da contribuição do escoamento subterrâneo proporcionado pelo fluxo regional e corresponde a vazão de quase $29 \mathrm{~m}^{3} / \mathrm{s}$ ou pouco mais de $13 \%$ do escoamento de base do SAU para a Bacia do Rio Tocantins. Esse fluxo regional não é desprezível, considerando que poderia manter mais de 600 poços em operação contínua, extraindo vazão de $200 \mathrm{~m}^{3} / \mathrm{h}$ em regime de bombeamento de 20 horas diárias. Outra questão a ser levantada é que o volume de água captado dos aquíferos permo-triassicos, por poços profundos na porção centro-norte da Bacia Sanfranciscana, interfere no escoamento de base dos rios contribuintes da Bacia do Tocantins e não no escoamento de base da Bacia do Rio São Francisco.

\section{CONCLUSÕES}

A porção centro-norte da Bacia Sanfranciscana revelou a presença de aquíferos permo-triassicos, associados às formações Motuca e Sambaíba, da Bacia do Parnaíba, subjacentes ao Sistema Aquífero Urucuia. Embora conectadas, essas unidades hidroestratigráficas integram contextos hidrogeológicos distintos governados, respectivamente, por sistemas locais e regionais de fluxo subterrâneo.

Os sistemas locais de fluxo são responsáveis pela descarga de água subterrânea do SAU na forma de escoamento de base dos cursos de água superficiais, para os rios São Francisco $\left(731 \mathrm{~m}^{3} / \mathrm{s}\right)$, Tocantins $\left(215 \mathrm{~m}^{3} / \mathrm{s}\right)$ e Parnaíba ( $\left.45 \mathrm{~m}^{3} / \mathrm{s}\right)$. 0 sentido principal do escoamento subterrâneo é de oeste para leste, acompanhando o sentido do escoamento superficial.

O fluxo regional é representado pelo escoamento profundo das águas subterrâneas armazenadas nos aquíferos permo-triassicos. O escoamento regional dirige-se para NW, paralelo ao eixo longitudinal da Bacia Sanfranciscana, conduzindo as águas subterrâneas para a Bacia do Rio Tocantins. A vazão transferida pelo fluxo regional para essa bacia foi estimada em $29 \mathrm{~m}^{3} / \mathrm{s}$, todavia, estudos hidrogeológicos detalhados devem ser realizados para uma avaliação efetiva.

Outro aspecto importante refere-se à dominialidade dos recursos hídricos subterrâneos, que de acordo com legislação brasileira é estadual. Os estados têm o direito de administrar as concessões e outorgas de água subterrânea dos aquíferos presentes nos respectivos subsolos. O Sistema Aquífero Urucuia recobre toda a área da porção centro-norte da Bacia Sanfranciscana e o escoamento subterrâneo considerado para a gestão de recursos hídricos refere-se somente às vazões produzidas pelos fluxos locais, no âmbito dos limites estaduais. Todavia, a retirada de águas subterrâneas dos reservatórios permo-triassicos, por meio de poços profundos, interfere no escoamento de base dos rios do Estado do Tocantins. Portanto, os modelos de gestão de águas subterrâneas discutidos para a área do SAU, na porção centro-norte da Bacia Sanfranciscana, de vem ser reavaliados perante os comitês estaduais envolvidos, face às peculiaridades hidrogeológicas dessa região.

\section{REFERÊNCIAS}

ANA - AGENCIA NACIONAL DE ÁGUAS. Estudos hidrogeológicos na Bacia Hidrográfica do São Francisco - Sistema Aquífero Urucuia/Areado e Sistema Aquífero Bambuí. Comitê Bacia Hidrográfica do São Francisco. 2013. http://cbhsaofrancisco.org.br.

ANA - AGENCIA NACIONAL DE ÁGUAS. Gestão integrada de recursos hídricos superficiais e subterrâneos: Sistemas aquíferos Urucuia e Bambui. REUNIÃO PLENÁRIA DO COMITÊ DA BACIA HIDROGRÁFICA DO RIO SÃO FRANCISCO, 29., 2016. Anais... 2016. cbhsaofrancisco.org. http://cbhsaofrancisco.org.br.

AQUINO, R. F. de; NASCIMENTO, K. R. F.; RODRIGUES, Z. R.; VIEIRA, C.; MAIA P. H. P. \& COSTA, A. B. Caracterização hidrogeoquímica e isotópica das águas superficiais e subterrâneas do oeste baiano - Bacia do rio das Fêmeas Bahia. In: SIMPÓSIO BRASILEIRO DE RECURSOS HÍDRICOS, 15, 2003, Curitiba (PR). Anais... Curitiba:ABRH, 2003.

CAMPOS, J. E. \& DARDENNE, M. A. Origem e evolução tectônica da Bacia Sanfranciscana. Revista Brasileira de Geociências. v. 27, 3, p. 283-294. 1997.

CHANG, H. K.; PAULA e SILVA, F. Contribuição ao arcabouço geológico do Sistema Aquífero Urucuia. Geociências, v. 34, n. 4, p.872-882. 2015.

CPRM - COMPANHIA DE PESQUISA DE RECURSOS MINERAIS. Mapa de domínios e subdomínios hidrogeológicos do Brasil. SIG, 2007.

EBERTS, S. \& GEORGE, L.L. Regional ground-water flow and geochemistry in the midwestern basins and arches aquifer system in parts of indiana, Ohio, Michigan, and Illinois. Regional aquifer-system analysis-Midwestern basins and arches. U.S. Geological Survey Professional paper 1423-C. 2000.

FETTER, C.W. Applied hydrogeology. Prentice Hall. 2001. 598 p.

GASPAR, M.T.P. Sistema Aquífero urucuia: caracterização regional e propostas de gestão. Tese (Doutorado) - Universidade de Brasília, 2006. 158 p.

LIMA, E. A. M. \& LEITE, J. F. Projeto estudo global dos recursos minerais da Bacia Sedimentar do Parnaíba: integração geológico-metalogenética. Relatório final da etapa III. 1978.

LIMA, O. A. L. Estudos geológicos e geofísicos do aquífero urucuia na bacia do rio do cachorro - Oeste da Bahia. 42 p. Publicação da SRH-BA e UFBA. 2000.

PEREIRA, C.; FARIAS, A.L.; MORAIS NETO, J.M,; GELLI, R.B.; MIRANDA, L.G.; CAPUCCI, F.V. \& TROSDTORF JÚNIOR, I. New Processing and Seismic Interpretation for the Northern São Francisco Basin, Brazil. 14th International Congress of the Brazilian Geophysical Society, Anais.... Rio de Janeiro, Brazil. 2015.

PETRI, S. \& FÚLVARO, V. J. Geologia do Brasil (Fanerozóico). São Paulo: T. A. Queiroz, USP. 631p. 1983.

SCHUSTER H.D.M, SILVA F.F., TEIXEIRA S.L., BATISTA L.H.G. \& FREITAS W.A. Estudos Hidrogeológicos do Aquífero Urucuia no Oeste baiano para Obtenção de Parâmetros nas outorgas de mananciais Subterrâneos. In: ABAS, CONGRESSO BRASILEIRO DE ÁGUAS SUBTERRÂNEAS, 12. Anais.. Santa Catarina, CD-ROM. 2002.

SGARBI, G.N.C. Geologia da formação areado, cretáceo médio a inferior da Bacia do São Francisco, oeste do Estado de Minas Gerais. Dissertação (Mestrado)- Universidade Federal do Rio de Janeiro.. 1989. 324 p 